\title{
Design Charts to Assist on the Sizing of Natural Ventilation for Cooling Residential Apartments in India
}

\author{
de Faria, Luciano $\mathrm{C}^{1}$, Cook, Malcolm $\mathrm{J}^{1}$; Loveday, Dennis ${ }^{1}$; Angelopoulos, Charalampos ${ }^{1}$; Shukla, \\ $\mathrm{Yash}^{2}$, Rawal, Rajan ${ }^{2}$; Manu, Sanyogita ${ }^{2}$; Mishra, Deepta ${ }^{2}$; Patel, Jayamin ${ }^{2}$, Anbarasu, Saranya ${ }^{2}$ \\ ${ }^{1}$ School of Architecture, Building and Civil Engineering, Loughborough University, UK \\ ${ }^{2}$ CEPT University, India
}

\begin{abstract}
This paper presents four design charts (DC) to work as a simplified, easy-to-use and cost-effective tool to assist architects and building designers on sizing openings to deliver natural ventilation (NV) for cooling. The DC are derived from analytical techniques for four NV design systems based either on buoyancy-driven or wind-driven flow. The application of the DC is demonstrated to size NV openings for a bedroom in an apartment located in three Indian cities for two opening size scenarios: 'business as usual' (A); and 'necessary size' (B) to deliver the desired ventilation rates for cooling. The ventilation rates for cooling found with these DC are compared with outputs from computational fluid dynamics simulations. Findings show that for the earlier design stage the derived DC are effective tools. It is also found that the opening sizes used in scenario A do not deliver the desired NV rates for cooling, whilst the openings for scenario B must be sized separately for each city to be effective.
\end{abstract}

\section{Introduction}

Energy consumption for cooling buildings in India increased fifteen-fold in the past three decades and this growth rate is expected to continue to 2050 (OECD/IEA, 2018). A large number of air-conditioned (AC) systems will be installed in new residences, and this rise in energy demand could exceed the national energy supply capacity (Rawal and Shukla, 2014).

The increase in the use of natural ventilation (NV) for cooling presents an alternative to $\mathrm{AC}$. $\mathrm{NV}$ has the potential to deliver thermal comfort and reduce energy demand whilst avoiding unnecessary AC. However, the successful design of NV strategies for cooling involves expertise and time. Ideal approaches for this task would comprise, for example, physical experiments with reduced scale models in wind-tunnel or CFD simulations. While these methods are available for academic research and industry, they may not be accessible for architecture offices on a daily basis.

This work presents four design charts (DC) derived using analytical techniques (CIBSE, 2005; CIBSE, 2010) for sizing openings for cooling NV for residences. The DC provide a simplified, easy-to-use and cost-effective alternative intended to assist architects and building designers at the concept design stage of buildings, when decisions about NV strategies for cooling are made and openings for NV are defined and sized.
The DC are based on inside-outside air temperature difference, internal heat gains, wind speed and wind pressure and are applicable for a wide range of weather conditions. The DC-1 and DC-2, which are based on buoyancy-driven flow, can be used for $\Delta \mathrm{T}_{\text {inside-outside }}$ of up to $10^{\circ} \mathrm{C}$, and the $\mathrm{DC}-3$ and $\mathrm{DC}-4$, which are based on wind-driven flow, can be used for wind speeds of up to $5.00 \mathrm{~m} / \mathrm{s}$ and $\Delta \mathrm{Cp}$ of up to 1.00 . This ranges of weather conditions are adequate for the locations and climatic regions covered in this paper. Examples of use of the DC are demonstrated for a bedroom of a typical two-bedroom apartment layout considered to be located in three climate-representative cities in India: Ahmedabad (AHM - Hot-dry), New Delhi (DEL - Composite) and Mumbai (MUM - Warm-humid).

Two scenarios of use of the DC are demonstrated: an analysis of the capacity of the openings with the dimensions designed as business as usual (BAU) to deliver NV (scenario A); and the sizing of the openings with the necessary dimensions and areas to deliver the desired ventilation rates for cooling (scenario B). The rates identified with the $\mathrm{DC}$ are compared with detailed computational fluid dynamics (CFD) simulations for the same arrangements of opening sizes and NV systems.

\section{Method}

The following steps are described in this research work:

- The weather data are analysed and the feasibility for $\mathrm{NV}$ is identified for three Indian cities.

- The desired ventilation rates for cooling a master bedroom in a typical two-bedroom residential apartment are calculated.

- Four DC derived using analytical techniques for sizing $\mathrm{NV}$ are presented. On the DC presented, ventilation rates are identified for Scenario A and for Scenario B.

- These rates are compared with outputs from CFD simulations.

- Results are discussed and conclusions are drawn.

\section{Weather data and feasibility for NV}

Weather data used in this work comes from the Indian Society of Heating Refrigeration and Air-conditioning Engineers (ISHRAE) downloaded from the Climate.OneBuilding.Org (2014) web page. A previous feasibility study to identify the extent of comfort hours in apartments suggests that NV does not provide thermal comfort all year-round (Manu et al., 2016). The criteria used in this work to sort the weather data and identify 
when NV is feasible was based on: the India Model for Adaptive Comfort (IMAC) from Manu et al. (2016), relative humidity $(\mathrm{RH})$ thresholds (between $30 \%$ and $70 \%$ ) and inside-to-outside air temperature difference. The inside air temperature used to calculate the inside-tooutside temperature difference was assumed to be equal to the calculated neutral temperature using the IMAC for an acceptability band of $80 \%$, and this criterion is covered in detail in other paper from the authors (de Faria et al, 2018). Hours for which the inside-to-outside temperature difference results in negative values were rejected, since $\mathrm{NV}$ for cooling is not feasible to happen. Table 1 presents the hours of the year for which the use of NV is feasible. The hours were sorted between night-time and day-time based on the values for global horizontal radiation (GHR). The GHR consists of the total amount of solar radiation falling on a horizontal surface, thus indicating day-time.

Table 1: Hours of the year for which NV is feasible in three Indian cities (as percentage and number of hours)

\begin{tabular}{|c|c|c|c|c|c|c|c|c|c|}
\hline & \multicolumn{3}{|c|}{ AHM } & \multicolumn{3}{c|}{ DEL } & \multicolumn{3}{c|}{ MUM } \\
\cline { 2 - 10 } & day & night & total & day & night & total & day & night & total \\
\hline \% & $9 \%$ & $21 \%$ & $\mathbf{3 0 \%}$ & $12 \%$ & $13 \%$ & $\mathbf{2 5 \%}$ & $7 \%$ & $9 \%$ & $\mathbf{1 6 \%}$ \\
\hline hours & 832 & 1,848 & $\mathbf{2 , 6 8 0}$ & 1,016 & 1,165 & $\mathbf{2 , 1 8 1}$ & 596 & 771 & $\mathbf{1 , 3 6 7}$ \\
\hline
\end{tabular}

\section{Desired ventilation rates for cooling}

The desired ventilation rates for cooling a bedroom, the master bedroom (MB), in a typical two-bedroom residential apartment, the type 02BHK Case-1 (Rawal and Shukla, 2014) (Figure 1), was found for the three cities.

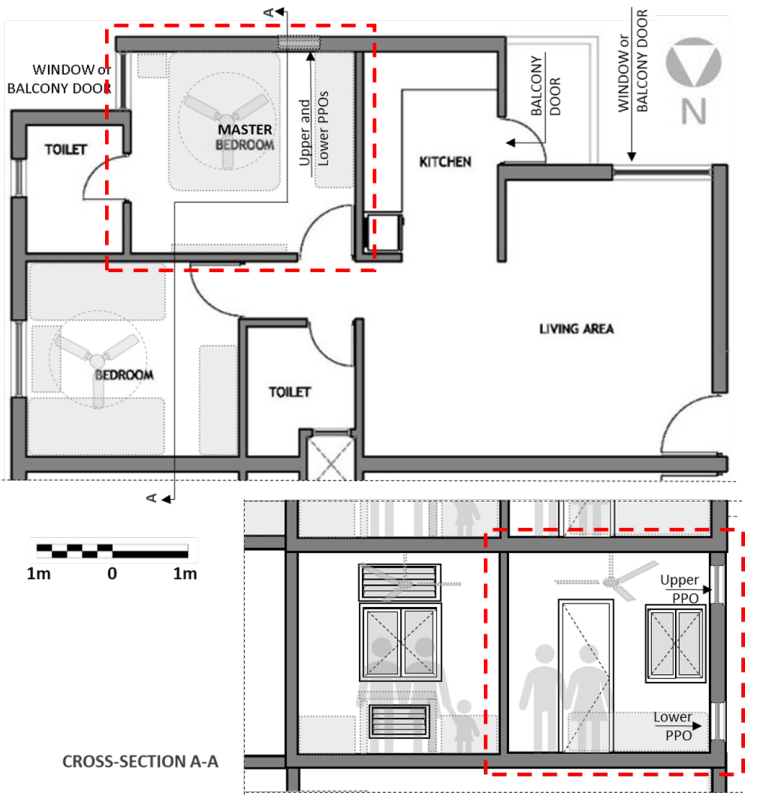

Figure 1: MB (dashed red line) and the apartment employed in this work (Rawal and Shukla, 2014).

In order to calculate the desired ventilation rates, it is necessary to know the total heat gains for this room. The total heat gains were calculated by adding the heat gains from occupants, equipment and heat exchange balance between inside and outside. The inside-to-outside heat exchange (gains and losses) per square metre of the envelope was obtained by modelling the MB in Design-
Builder software and then simulating in Energy-Plus dynamic thermal modelling software. Heat gains from equipment and building envelope properties for BAU constructions were used from the Rawal and Shukla (2014). Two occupants were assigned in this room, and different metabolic rates and use of equipment were considered for day and night (CIBSE, 2010) for an occupancy schedule. Eventually, the desired ventilation rates were calculated using equation 1 (CIBSE, 2011).

$$
q_{\text {des }}=\frac{Q_{\text {total }}}{\rho C_{p} \Delta T_{\text {inside-outside }}}
$$

The desired ventilation rates were calculated only for the hours of the year for which NV is feasible (Table 1) and are shown in Figure 2. For the demonstration of the DC the values used were found at the third quartile of the chart in Figure 2. These values used correspond to $75 \%$ of the hours for which NV is feasible and are given in Table 2.

Table 2: Desired ventilation rates for cooling for the $M B$ for $75 \%$ of the hours for which $N V$ is feasible.

\begin{tabular}{|c|c|c|c|}
\hline Flow rates & AHM & DEL & MUM \\
\hline $\mathbf{q}_{\text {des }}\left(\mathbf{m}^{3} / \mathbf{s}\right)$ & 0.41 & 0.34 & 0.54 \\
\hline $\mathbf{A C H}$ & 45 & 37 & 59 \\
\hline
\end{tabular}

Based on the values from Table 1 and Table 2 it is possible to say that, in Ahmedabad, a ventilation rate of $0.41 \mathrm{~m}^{3} / \mathrm{s}$ has the potential to remove via $\mathrm{NV}$ the heat gains in a typical bedroom size for up to 2,010 hours of the year.

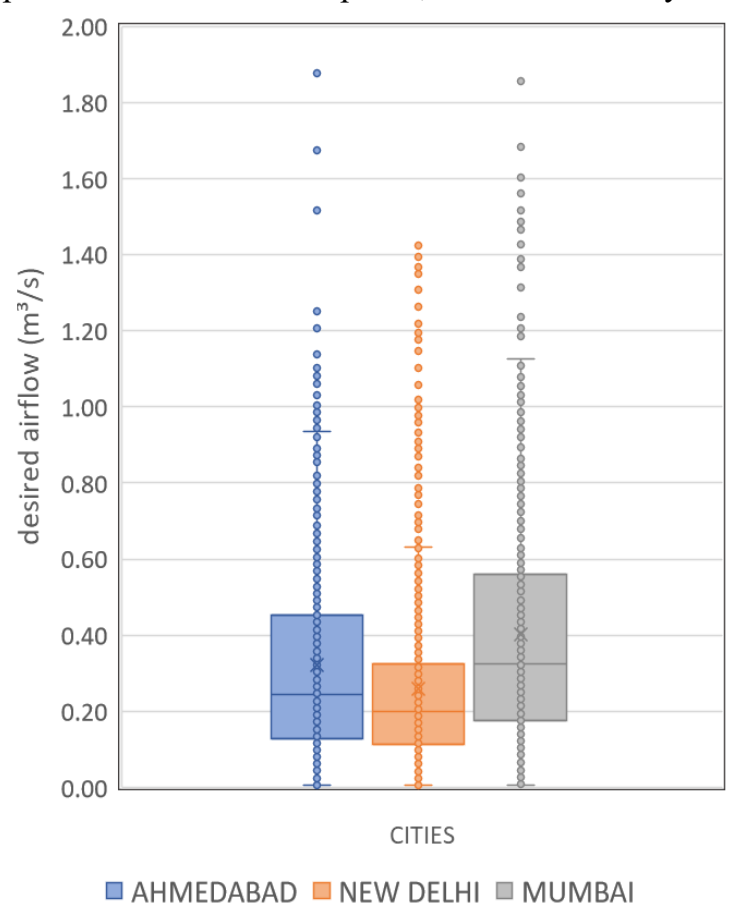

Figure 2: Desired rates for cooling a bedroom in three Indian cities, calculated for when $\mathrm{NV}$ is feasible.

Furthermore, several standards report about minimum ventilation rates for indoor air quality (IAQ). For example, the suggested air supply rates for IAQ in bedrooms range from 0.4-1.0 air changes per hour $(\mathrm{ACH})$ (CIBSE, 2010) when outdoor air quality satisfies minimum standards. The desired NV cooling rates shown in Table 2 surpass the IAQ rates by a large amount. 


\section{Design charts for sizing NV}

Four DC to size openings for NV are presented in this work. These DC are derived from analytical techniques described in CIBSE AM-10 guide for the design and application of NV in non-domestic buildings (CIBSE, 2005) for four NV design systems. The four NV design systems are sketched in Figure 3 and listed here:

- NV design system 1: buoyancy-driven flow; single-sided ventilation with one opening (Figure 3a)

- NV design system 2: buoyancy-driven flow; cross-ventilation with multiple openings (Figure $3 b$ )

- NV design system 3: wind-driven flow; single-sided ventilation with one opening (Figure 3c)

- NV design system 4: wind-driven flow; cross-ventilation with multiple openings (Figure 3d)

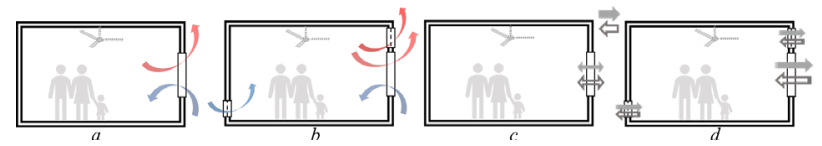

Figure 3: Cross-section sketches of the driving forces for four NV design systems.

A single opening is used for the arrangements of $\mathrm{NV}$ design systems in Scenario A: the 'window 1xA' (Figure 4). The 'window $2 \mathrm{xA}^{\mathrm{A}}$ ' and the 'balcony door $3 \mathrm{xA}^{\mathrm{A}}$ ' are also shown as examples of how to increase the effective open area for NV whilst maintaining the same width of the opening. For the arrangements with multiple openings two purpose provided openings (PPOs) (Jones et al., 2016) are inserted in the bedroom (one near the ceiling and other near the floor). The total area of the PPOs was assumed to be the same as the window or balcony door area adopted for the arrangement with a single opening.

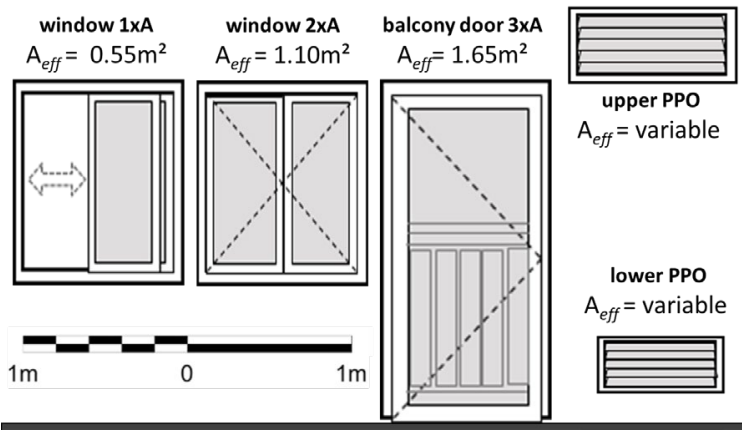

Figure 4: Schematic view of the openings for ventilation used in this work (Faria et al., 2018).

Finally, the four DC to size openings for NV are presented in this work (Figures 5 to 8). Two scenarios of usage demonstrated for each DC are also presented in Figures 5 to 8. In Scenario A (represented by the dashed red line in Figures 5 to 8 ) the maximum ventilation rates which can be achieved with BAU opening size are identified. In Scenario B (represented by the full red line in Figures 5 to 8 ) the necessary opening sizes to deliver the desired rates given in Table 2 are identified. Table 3 summarizes the input parameters for the demonstrations of both scenarios, these values being found during the weather analysis and, as an example of the calculation for the desired rates, also correspond to $75 \%$ of the hours for which NV is feasible.
Table 3: Input parameters employed for the demonstration of the $D C$.

\begin{tabular}{|c|c|c|c|}
\hline Input parameters & AHM & DEL & MUM \\
\hline$\Delta \mathbf{T}_{\text {inside-outside }}(\mathbf{K})$ & 8.9 & 7.0 & 5.3 \\
\hline Wind speed at $\mathbf{V}_{\mathbf{z}}(\mathbf{m} / \mathbf{s})$ & 2.7 & 1.0 & 1.4 \\
\hline $\boldsymbol{\Delta C p}$ & 0.36 & 0.36 & 0.36 \\
\hline
\end{tabular}

DC-1: Design chart for a NV design system with buoyancy-driven flow and single-sided single opening

This DC is used to predict ventilation rates or opening sizes for an NV design system consisting of a single opening in a room (e.g. a window) and induced by buoyancy force. In this system, due to density difference, the inside hot air rises and exits from the upper section of the opening, being replaced by cold air supplied by the lower section. The DC-1 (Figure 5) is derived from Equation 2 (CIBSE, 2005). For single openings the discharge coefficient is 0.25 (CIBSE, 2005).

$$
A_{\text {eff }}=\frac{q_{\text {req }}}{C_{d}} \sqrt{\frac{\left(T_{\text {inside }}+273\right)}{g h \Delta T_{\text {inside-outside }}}}
$$

DC-2: Design chart for a NV design system with buoyancy-driven flow and multiple openings

The design chart for NV induced by buoyancy with multiple openings, DC-2 (Figure 6), is also based on Equation 2. The same concept of air density described for the DC-1 repeats here. However, as a result of having multiple openings, the ones positioned below the neutral pressure level supply cool air while warm air exits from the ones positioned above this level. The greater is the distance between the lower inlet opening and the upper outlet opening, then the more efficient this NV system will be. Since inflow and outflow occur via different openings the discharge coefficient adopted is 0.60 (CIBSE, 2005; Heiselberg and Sandberg, 2006).

\section{DC-3: Design chart for a NV design system with wind-driven flow and single-sided single opening}

For NV via a single opening on which the flow is mainly induced by wind, the driven pressure is a result of the wind speed. The wind speed is calculated based on the height of the opening and the wind profile adjusted according to the terrain roughness. Although wind is random and variable, prevailing directions may be considered when choosing building shape and opening size, type and orientation whenever possible to maximize ventilation. Furthermore, a rule of thumb advises that a ratio between room depth and ceiling height of 2.5 is the limit for efficient single-sided wind-driven NV (CIBSE, 2010). The size of the opening is found using the DC-3 (Figure 7), based on Equation 3 and for an opening shape coefficient (C) of 0.05 (CIBSE, 2005).

$$
\mathrm{A}_{\text {eff }}=\mathrm{q}_{\mathrm{req}} / \mathrm{CV}_{\mathrm{z}}
$$

DC-4: Design chart for a NV design system with wind-driven flow and multiple openings

NV systems based on wind-driven cross-ventilation are result of pressure differences on two or more openings acting separately as inlet or outlet. Wind across a building creates positive pressure on the windward side and 
negative pressure on the leeward side. The pressure difference between openings and across the internal space results in crossed airflow. A rule of thumb advises the ratio between room depth and ceiling height of 5 as the limit for efficient cross-ventilation (CIBSE, 2010). Wind pressure distribution on the building envelope is not homogeneous. Furthermore, it is never steady and the pulsating and intermittent characteristic of turbulent flow in urban areas should be considered to determine ventilation rates. If not considered, then the resulting ventilation rates may differ even for windows with the same size and positioned side by side in a building façade (Awbi, 2003; CIBSE, 2010). The DC-4 (Figure 8), based on Equation 4 (CIBSE, 2005), is used to size openings or rates for cross-ventilation wind-driven systems.

$$
\mathrm{A}_{\text {eff }}=\mathrm{q}_{\mathrm{total}}\left(\mathrm{C}_{\mathrm{d}} \mathrm{V}_{\mathrm{z}} \sqrt{\frac{\Delta \mathrm{C}_{p}}{2}}\right)^{-1}
$$

For two or more openings the discharge coefficient ranges from 0.60 to 0.90 according to characteristics of the window frame and opening (CIBSE, 2005; Heiselberg and Sandberg, 2006), and the DC-4 presented here uses the former value. Pressure coefficients for orthogonal and oblique wind directions for the building shape used in this research are from CIBSE Guide A (CIBSE, 2010). For orthogonal wind, a pressure coefficient difference between inlets and outlets of 0.36 is adopted (Table 3 ).

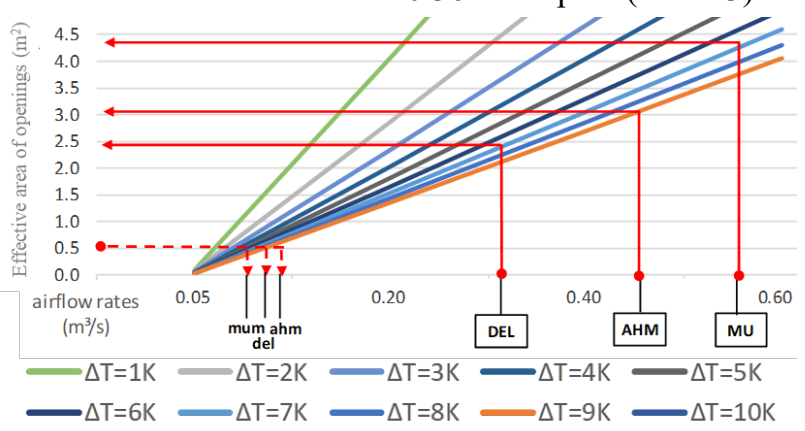

scenario $A$ - - - - scenario $B$

Figure 5: Design Chart 1 for NV design systems based on single-sided single opening buoyancy-driven force.

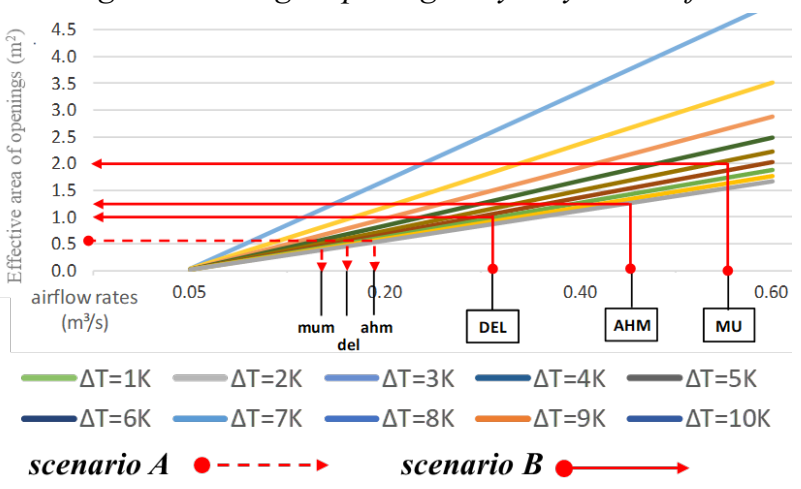

Figure 6: Design Chart 2 for NV design systems based on multiple openings and buoyancy-driven force.

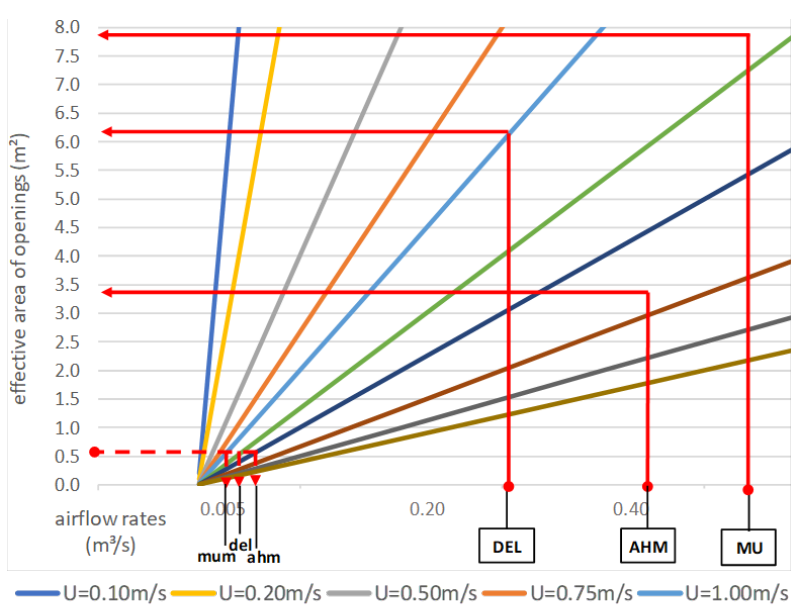

$-U=0.10 \mathrm{~m} / \mathrm{s}-\mathrm{U}=0.20 \mathrm{~m} / \mathrm{s}-\mathrm{U}=0.50 \mathrm{~m} / \mathrm{s}-\mathrm{U}=0.75 \mathrm{~m} / \mathrm{s} \longrightarrow \mathrm{U}=1.00 \mathrm{~m} / \mathrm{s}$

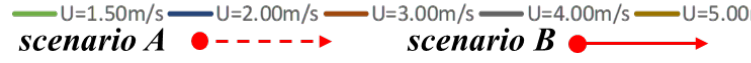

Figure 7: Design Chart 3 for NV design systems based on single-sided single openings and wind-driven force.

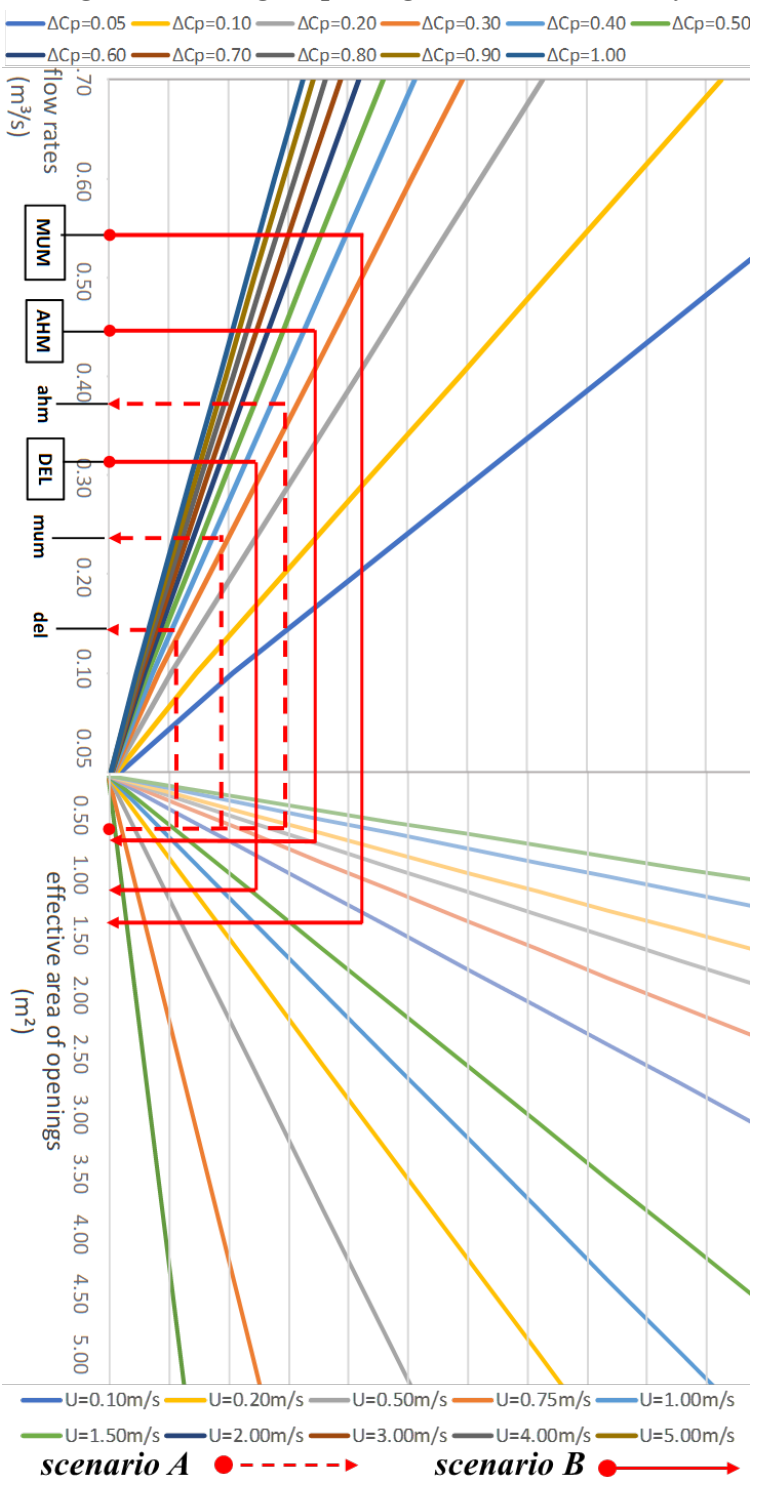

Figure 8: Design Chart 4 for NV design systems based on multiple openings and wind-driven force. 


\section{Results from the demonstrations}

Utilizing the four DC presented, the ventilation rates which can be achieved with the opening size adopted for Scenario A ('window 1xA', from Figure 4) and the input parameters (Table 3) are shown in Table 4.

Table 4: Achieved ventilation rates for Scenario A.

\begin{tabular}{|c|c|c|c|c|c|}
\hline $\begin{array}{c}\text { Design } \\
\text { charts }\end{array}$ & $\begin{array}{c}\text { NV driven } \\
\text { force }\end{array}$ & $\begin{array}{c}\text { Number of } \\
\text { openings }\end{array}$ & $\begin{array}{c}\text { AHM } \\
\text { qach } \\
\left(\mathrm{m}^{3} / \mathrm{s}\right)\end{array}$ & $\begin{array}{c}\text { DEL } \\
\text { qach } \\
\left(\mathrm{m}^{3} / \mathrm{s}\right)\end{array}$ & $\begin{array}{c}\text { MUM } \\
\text { qach } \\
\left(\mathrm{m}^{3} / \mathrm{s}\right)\end{array}$ \\
\hline DC-1 & buoyancy & single & 0.08 & 0.07 & 0.06 \\
\hline DC-2 & buoyancy & multiple & 0.19 & 0.17 & 0.15 \\
\hline DC-3 & wind & single & 0.07 & 0.03 & 0.04 \\
\hline DC-4 & wind & multiple & 0.38 & 0.14 & 0.20 \\
\hline
\end{tabular}

Comparing these ventilation rates with the desired values (see Table 2), it is possible to conclude that the opening sizes adopted in scenario A cannot provide the desired ventilation rates. Conversely, the necessary sizes of openings to deliver the desired ventilation rate (Scenario B) can also be identified via the design charts and are presented in Table 5 .

Table 5: Necessary window opening areas to achieve the desired ventilation rates for cooling (Scenario B).

\begin{tabular}{|c|c|c|c|c|c|}
\hline $\begin{array}{c}\text { Design } \\
\text { charts }\end{array}$ & $\begin{array}{c}\text { NV driven } \\
\text { force }\end{array}$ & $\begin{array}{c}\text { Number of } \\
\text { openings }\end{array}$ & $\begin{array}{r}\text { AHM } \\
\mathbf{A}_{\text {eff }} \\
\left(\mathrm{m}^{2}\right)\end{array}$ & $\begin{array}{r}\text { DEL } \\
\mathbf{A}_{\text {eff }} \\
\left(\mathrm{m}^{2}\right)\end{array}$ & $\begin{array}{c}\text { MUM } \\
\mathbf{A}_{\text {eff }} \\
\left(\mathrm{m}^{2}\right.\end{array}$ \\
\hline DC-1 & buoyancy & single & 2.79 & 2.61 & 4.75 \\
\hline DC-2 & buoyancy & multiple & 1.15 & 1.09 & 2.00 \\
\hline DC-3 & wind & single & 3.04 & 6.80 & 7.71 \\
\hline DC-4 & wind & multiple & 0.60 & 1.35 & 1.52 \\
\hline
\end{tabular}

The sizes of the openings found for Scenario B are all greater than those from Scenario A and vary considerably based on the DC utilised. The most effective solutions are those which combine openable windows or balcony-doors with PPOs for ventilation allowing cross-ventilation (DC2 and DC-4). Furthermore, the sizes of the openings vary for each city. For example, using the DC-1, it is found that an opening of $A_{\text {eff }}$ of $2.79 \mathrm{~m}^{2}$ is necessary in Ahmedabad. When compared to the opening size used in Scenario A, this represents an increase of more than five times. To have an opening with such area, either a window with $2.35 \times 1.20 \mathrm{~m}(\mathrm{~W} \times \mathrm{H})$ or a balcony door with $1.40 \times 2.05 \mathrm{~m}$ is necessary. None of these two options physically fit in the apartment layout analysed and, therefore, cannot be built. Conversely, the necessary opening area for multiple openings found with the DC-2 $\left(1.15 \mathrm{~m}^{2}\right)$ could be obtained by changing the opening mechanism from a horizontal sliding to a double sided-hung casement type (for example, the 'window $2 \mathrm{xA}^{\text {' }}$ in Figure 4), and incorporating PPOs. Also, the necessary opening area for multiple openings and wind found with the DC-4 $\left(0.60 \mathrm{~m}^{2}\right)$ is very close to the one used in Scenario A. On the other hand, the values found for Mumbai with singlesided single opening NV systems (DC-1 and DC-3) may be unfeasible for most apartments, and arrangements with multiple openings, such as the one combining a large balcony door with extra PPOs for ventilation, is necessary.

\section{Results from the CFD simulations}

The successful use of the DC presented is related to their capacity to accurately predict ventilation rates or identify opening sizes for NV. To verify this, a total of eighteen CFD simulations were performed in this work to provide results of airflow for comparison with the values from the $\mathrm{DC}$ for both the scenarios A and B. Table 6 shows the arrangements of NV design systems and opening sizes simulated in CFD to compare with Scenario A.

Table 6: CFD arrangements for comparison with Scenario A

\begin{tabular}{|c|c|c|c|c|c|c|}
\hline n. & $\begin{array}{c}\text { Design } \\
\text { charts }\end{array}$ & City & $\begin{array}{c}\text { NV driven } \\
\text { force }\end{array}$ & $\begin{array}{c}\text { N. of } \\
\text { openings }\end{array}$ & $\begin{array}{c}\text { Window } \\
\mathbf{A}_{\text {eff }}\end{array}$ & $\begin{array}{c}\text { PPOs } \\
\mathbf{A}_{\text {eff }}\end{array}$ \\
\hline $\mathbf{1}$ & DC-1 & AHM & buoyancy & single & 0.55 & - \\
\hline $\mathbf{2}$ & DC-2 & AHM & buoyancy & multiple & 0.55 & - \\
\hline $\mathbf{3}$ & DC-3 & AHM & wind & single & 0.55 & 0.55 \\
\hline $\mathbf{4}$ & DC-4 & AHM & wind & multiple & 0.55 & 0.55 \\
\hline $\mathbf{5}$ & DC-1 & DEL & buoyancy & single & 0.55 & - \\
\hline $\mathbf{6}$ & DC-2 & DEL & buoyancy & multiple & 0.55 & - \\
\hline $\mathbf{7}$ & DC-3 & DEL & wind & single & 0.55 & 0.55 \\
\hline $\mathbf{8}$ & DC-4 & DEL & wind & multiple & 0.55 & 0.55 \\
\hline $\mathbf{9}$ & DC-1 & MUM & buoyancy & single & 0.55 & - \\
\hline $\mathbf{1 0}$ & DC-2 & MUM & buoyancy & multiple & 0.55 & - \\
\hline $\mathbf{1 1}$ & DC-3 & MUM & wind & single & 0.55 & 0.55 \\
\hline $\mathbf{1 2}$ & DC-4 & MUM & wind & multiple & 0.55 & 0.55 \\
\hline
\end{tabular}

A second group of CFD simulations was done to test the accuracy of the proposed DC to predict the necessary sizes of the openings to deliver the desired ventilation rates, as intended in Scenario B. Conversely, some of the opening sizes in Table 5 are impracticable for the apartment investigated. For this reason, only the NV design systems and opening arrangements that have a feasible size, the ones found with the DC-2 and DC-4, were simulated in CFD. Furthermore, the openings were modelled with the largest size identified between these two design charts. Table 7 shows the arrangements and sizes of the openings modelled in CFD to compare with those from Scenario B.

Table 7: CFD arrangements for comparison with Scenario B

\begin{tabular}{|c|c|c|c|c|c|c|}
\hline n. & $\begin{array}{l}\text { Design } \\
\text { charts }\end{array}$ & City & $\begin{array}{c}\text { NV driven } \\
\text { force }\end{array}$ & $\begin{array}{c}\text { N. of } \\
\text { openings }\end{array}$ & $\begin{array}{c}\text { Window } \\
\mathbf{A}_{\text {eff }}\end{array}$ & $\begin{array}{c}\text { PPOs } \\
\mathbf{A}_{\text {eff }}\end{array}$ \\
\hline $\mathbf{1 3}$ & DC-2 & AHM & buoyancy & multiple & 1.15 & 1.15 \\
\hline $\mathbf{1 4}$ & DC-4 & AHM & wind & multiple & 1.15 & 1.15 \\
\hline $\mathbf{1 5}$ & DC-2 & DEL & buoyancy & multiple & 1.35 & 1.35 \\
\hline $\mathbf{1 6}$ & DC-4 & DEL & wind & multiple & 1.35 & 1.35 \\
\hline $\mathbf{1 7}$ & DC-2 & MUM & buoyancy & multiple & 2.00 & 2.00 \\
\hline $\mathbf{1 8}$ & DC-4 & MUM & wind & multiple & 2.00 & 2.00 \\
\hline
\end{tabular}


All the CFD simulations used in this work were modelled with an academic version of the ANSYS ICEM R16.0 and pre-processed, solved and post-processed with an academic version of the general-purpose ANSYS CFX R19.1 code. The capacity of CFD simulations to reproduce airflow in the internal environment based on buoyancy and wind-driven forces has been largely explored and validated by several authors (Jiang et al., 2003; Jiang and Chen, 2003; Zhai et al., 2007; Lo et al., 2012; Durrani et al., 2015).

The input parameters for the boundaries utilized in all CFD models is shown in Table 8 . These values were found during the weather analysis and the calculation of the heat gains and, as an example of the calculation for the desired ventilation rates, also correspond to $75 \%$ of the hours for which NV is feasible.

Table 8: Boundary parameters for the CFD simulations

\begin{tabular}{|c|c|c|c|}
\hline Input parameters & AHM & DEL & MUM \\
\hline Air temperature inside $\left({ }^{\circ} \mathrm{C}\right)$ & 30.6 & 30.5 & 29.3 \\
\hline Air temperature outside $\left({ }^{\circ} \mathrm{C}\right)$ & 21.7 & 23.5 & 24.0 \\
\hline Surface temperature inside $\left({ }^{\circ} \mathrm{C}\right)$ & 30.6 & 30.5 & 29.3 \\
\hline Occupant surface temperature $\left({ }^{\circ} \mathrm{C}\right)$ & 33.5 & 33.5 & 33.5 \\
\hline Wind pressure (multiple openings) $(\mathrm{Pa})$ & 0.48 & 0.18 & 0.25 \\
\hline Wind pressure $($ single opening) $(\mathrm{Pa})$ & 0.22 & 0.07 & 0.09 \\
\hline$\Delta \mathrm{Cp}$ & 0.36 & 0.36 & 0.36 \\
\hline Buoyancy ref density $\left(\mathrm{kg} / \mathrm{m}^{3}\right)$ & 1.155 & 1.153 & 1.156 \\
\hline Mass fraction $(\mathrm{kg} / \mathrm{kg}$ dry air) & 0.011 & 0.016 & 0.017 \\
\hline
\end{tabular}

An example of the 3D model used for the simulation 17, (see Table 7) for Mumbai, is shown in Figure 9.

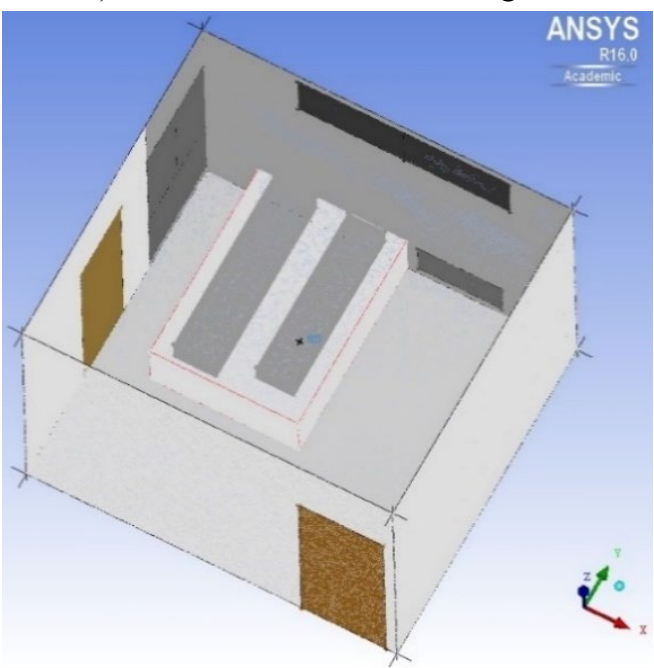

Figure 9: The 3D model used for the CFD simulation 17.

The CFX consists of a fully implicit solver based on finite method calculation (Versteeg and Malalasekera, 2007) and the CFD simulations were performed as steady-state mode with heat transfer to solve continuity equation settings. Turbulence mode k-Epsilon Scalable was selected for its capacity to model buoyancy flows (Yalkot et al., 1992; Ji and Cook, 2007). The convergence criteria for residual type was set as RMS for residual targets of up to 1e-06. Convergence time analysis for some monitored points and surfaces is shown in Table 9. The CFD simulations were allowed to run for at least 500 accumulated time steps. The mesh type was set as tetra/mixed patch independent, and a mesh sensitivity analysis is shown in Table 10. All the CFD simulations were done with mesh quality type 2 . An example of results for air velocity shown as vectors across the room and as contour lines on the openings is given in Figure 10 for the CFD simulation 17: buoyancy flow and multiple openings (DC-2) for Mumbai (see Table 7).

Table 9: Averaged results for accumulated timesteps for the CFD simulation 15: DC-2 and New Delhi.

\begin{tabular}{|c|c|c|c|}
\hline Monitored points and surfaces & $\mathbf{> 1 0 0}$ & $\mathbf{> 5 0 0}$ & $>\mathbf{1 0 0 0}$ \\
\hline Point 1 Head Temperature $1\left({ }^{\circ} \mathrm{C}\right)$ & 26.05 & 25.37 & 25.20 \\
\hline Point 2 Head Velocity $1(\mathrm{~m} / \mathrm{s})$ & 0.19 & 0.23 & 0.25 \\
\hline Surface 1 flow PPO Low $\left(\mathrm{m}^{3} / \mathrm{s}\right)$ & -0.05 & -0.05 & -0.06 \\
\hline Surface 2 flow PPO High $\left(\mathrm{m}^{3} / \mathrm{s}\right)$ & 0.07 & 0.09 & 0.09 \\
\hline Surface 3 flow Window A $\left(\mathrm{m}^{3} / \mathrm{s}\right)$ & 0.06 & 0.08 & 0.08 \\
\hline Surface 4 flow Window B $\left(\mathrm{m}^{3} / \mathrm{s}\right)$ & 0.05 & 0.06 & 0.06 \\
\hline Surface 5 flow Window C $\left(\mathrm{m}^{3} / \mathrm{s}\right)$ & -0.15 & -0.17 & -0.18 \\
\hline
\end{tabular}

Table 10: Averaged results for the mesh sensitivity analysis for the CFD simulation 2: DC-2 and Ahmedabad.

\begin{tabular}{|c|c|c|c|}
\hline Mesh quality & 1 & 2 & 3 \\
\hline Number of elements & $1,299,625$ & $3,887,965$ & $7,626,656$ \\
\hline Maximum size & 0.99948 & 0.99972 & 0.99987 \\
\hline Minimum size & 0.06456 & 0.00035 & 0.03870 \\
\hline Mean size & 0.83417 & 0.69302 & 0.64392 \\
\hline Point 1 Head Temperature $1\left({ }^{\circ} \mathrm{C}\right)$ & 26.22 & 27.19 & 27.23 \\
\hline Point 2 Head Velocity $1(\mathrm{~m} / \mathrm{s})$ & 0.18 & 0.10 & 0.09 \\
\hline Surface 1 flow PPO Low $\left(\mathrm{m}^{3} / \mathrm{s}\right)$ & -0.05 & -0.04 & -0.04 \\
\hline Surface 2 flow PPO High $\left(\mathrm{m}^{3} / \mathrm{s}\right)$ & 0.08 & 0.08 & 0.06 \\
\hline Surface 3 flow Window A $\left(\mathrm{m}^{3} / \mathrm{s}\right)$ & 0.07 & 0.04 & 0.05 \\
\hline Surface 4 flow Window B $\left(\mathrm{m}^{3} / \mathrm{s}\right)$ & 0.05 & 0.04 & 0.05 \\
\hline Surface 5 flow Window $\mathrm{C}\left(\mathrm{m}^{3} / \mathrm{s}\right)$ & -0.15 & -0.12 & -0.12 \\
\hline 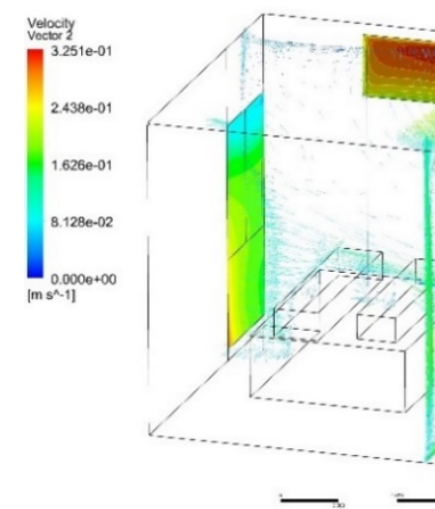 & 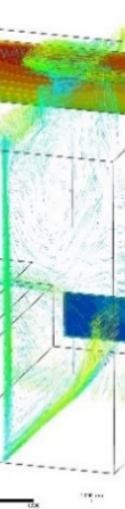 & & $i$ \\
\hline
\end{tabular}

Figure 10: Air velocity vectors and contour lines on the openings for the CFD simulation 17: DC-2 and Mumbai. 


\section{Comparison of the results from the design charts and the CFD simulations}

The comparison of the results of the ventilation rates obtained with the demonstration of the DC and from the CFD simulations is presented and discussed here.

The comparison of the results for Scenario A is shown in Figure 11. Results are given for each city and design chart and are also compared with the calculated desired ventilation rates for cooling. Good agreement is found between the ventilation rates predicted with the use of the $\mathrm{DC}$ and the ones from CFD. The averaged percentage difference between the values found with the DC and calculated in the CFD simulations for the twelve arrangements considered for Scenario A is only $1.00 \%$, and a maximum difference of $5 \%$. is shown for the MUM DC-4. The averaged discrepancy of the results between the two methods is of $\sim 0.02 \mathrm{~m}^{3} / \mathrm{s}$, with a maximum difference of $0.05 \mathrm{~m}^{3} / \mathrm{s}$ for MUM DC-4. Furthermore, the good level of agreement in the results corroborates with a previous statement made here that the opening sizes adopted for scenario A cannot provide the desired ventilation rates. The only exception is found for the results using the DC-4 for AHM. Both the values obtained from the DC-4 and the CFD simulation are $0.38 \mathrm{~m}^{3} / \mathrm{s}$, which are close to the desired ventilation rate of $0.41 \mathrm{~m}^{3} / \mathrm{s}$.

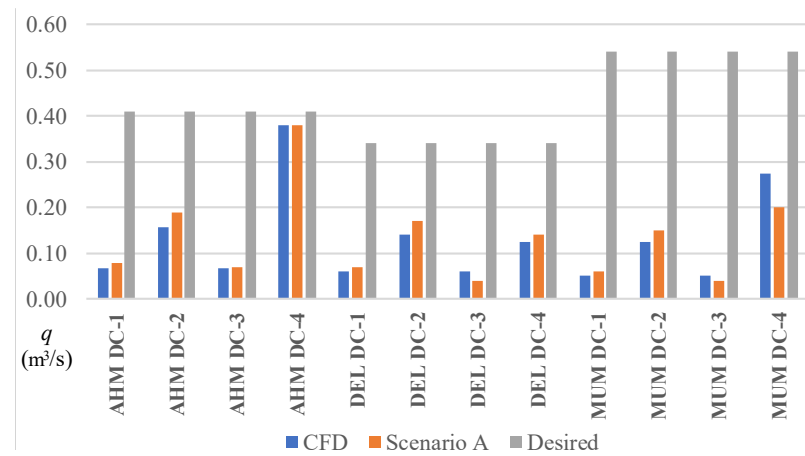

Figure 11: Comparison of the ventilation rates from the $C F D$ simulations and the design charts for Scenario $A$.

The results of the ventilation rates through the openings obtained with the CFD simulations for Scenario B are shown in Figure 12. This figure also shows the desired ventilation rates, since the objective of this scenario is to verify if the opening sizes previously identified using the design charts can achieve these rates. The results for the buoyancy-driven $\mathrm{NV}$ design system with multiple openings (DC-2) calculated in CFD are, on average, 35\% lower than what was expected for the opening sizes adopted (see Table 7). For Mumbai the difference reached $48 \%$ : a rate of $0.28 \mathrm{~m}^{3} / \mathrm{s}$ was simulated in CFD, while the expected result with the simulated opening sizes would be closer to $0.54 \mathrm{~m}^{3} / \mathrm{s}$.

The results from CFD for the wind-driven NV design system with multiple openings (DC-4) are, on average, $15 \%$ higher (for AHM and MUM) or lower (for DEL) than what was expected for the opening sizes. For Ahmedabad the difference is $19 \%$ : a rate of $0.51 \mathrm{~m}^{3} / \mathrm{s}$ was simulated in CFD, while the expected rate would be closer to $0.41 \mathrm{~m}^{3} / \mathrm{s}$. Conversely, since the sizes of the openings adopted for the CFD models were the largest between the sizes found with the DC-2 and the DC-4 (Table 5 and Table 7), the ones for Ahmedabad were oversized for wind-driven ventilation.

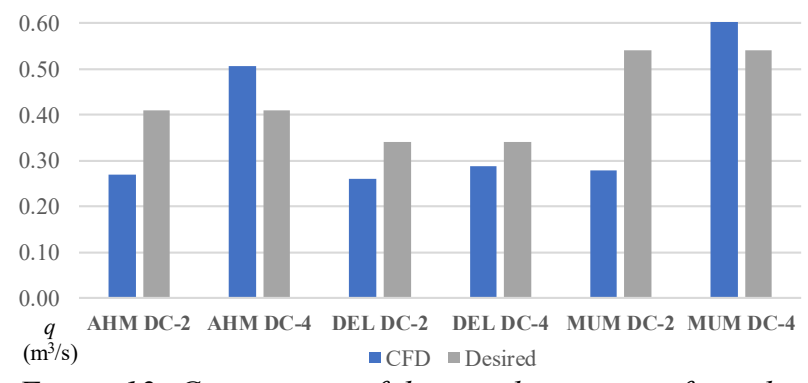

Figure 12: Comparison of the ventilation rates from the CFD simulations and the design charts for Scenario B.

\section{Conclusion}

This paper presents four design charts (DC) that can be employed as tools to assist in the sizing of openings for $\mathrm{NV}$ systems to deliver required ventilation rates for roomscale residential apartments located in three climatic regions across India.

The comparison of the values for two scenarios and for three Indian Cities obtained with the demonstration of the DCs and with CFD simulations leads to the conclusion that, for initial stages of residential building design, the four design charts can predict ventilation rates with a margin of error of less than $5 \%$.

Furthermore, the design charts can be used to determine the necessary sizes of the openings and the best arrangement of openings to deliver desired ventilation rates for wind-driven $\mathrm{NV}$ design systems with a margin of error of about $15 \%$.

With reference to the results for both the scenarios demonstrated, it is possible to say that the opening sizes adopted for current 'business as usual' designs (scenario A) cannot provide the desired ventilation rates for cooling. The results also show that a single opening for ventilation is less effective than multiple openings located in adjacent walls and at different heights.

To achieve the desired airflow rates for cooling, the openings must combine openable windows or balcony doors with purpose provided openings for NV, which need to be tailor sized for each location (scenario B).

Finally, to improve the accuracy of the design charts, notably the one for buoyancy-driven flow with multiple openings, more research is required. The DC may be in future derived from more complex CFD simulations validated with physical experiments and tested in more scenarios. This further research will allow a broader use of these design tools to be made to assist on decisions about NV strategies for residential buildings.

\section{Future work}

The analytical results from the design charts and the CFD simulations reported here are due to be further analysed via a dynamic thermal comfort model coupled with CFD and validated using a test facility at CEPT University, Ahmedabad, India. 


\section{Acknowledgement}

This research is part of an International collaboration with Loughborough University, UK, CEPT University, India, SE Controls UK and India, and supported by Indian project partners. The project is entitled: 'Low Energy Cooling and Ventilation for Indian Residences (LECaVIR)' and is financially supported by the UK Engineering and Physical Sciences Research Council (EPSRC) under grant reference: EP/ P029450/1. The authors express their gratitude for all support received.

\section{Nomenclature}

$\mathrm{A}_{\text {eff }}$ - effective open area of the openings for $\mathrm{NV}\left(\mathrm{m}^{2}\right)$

$\mathrm{A}_{\text {inlet }}$ - total area of inlet openings $\left(\mathrm{m}^{2}\right)$

$\mathrm{A}_{\text {outlet }}$ - total area of outlet openings $\left(\mathrm{m}^{2}\right)$

$\mathrm{C}$ - opening shape coefficient, ranging from 0.01 to 0.05

$\mathrm{C}_{\mathrm{d}}$ - discharge coefficient

$C_{p}-$ specific heat capacity of air $(\mathrm{J} / \mathrm{kg} \mathrm{K})$

$\mathrm{C}_{\mathrm{p}}$ - pressure coefficient

$\Delta \mathrm{C}_{\mathrm{p}}-$ pressure difference

$\Delta \mathrm{T}_{\text {inside-outside }}-\mathrm{T}_{\text {inside }}$ to $\mathrm{T}_{\text {outside }}$ temperature difference $(\mathrm{K})$

$\mathrm{g}$ - gravity force $\left(\mathrm{m} / \mathrm{s}^{2}\right)$

$\mathrm{h}$ - height of the opening for NV (m)

$Q_{\text {total }}$ - total heat gain (W)

$\rho$-density of air $\left(\mathrm{kg} / \mathrm{m}^{3}\right)$

$\mathrm{Pa}-$ dynamic pressure $(\mathrm{Pa})$

$q$ - ventilation rate $\left(\mathrm{m}^{3} / \mathrm{s}\right)$

$q_{a c h}-$ ventilation rate achieved $\left(\mathrm{m}^{3} / \mathrm{s}\right)$

$q_{d e s}-$ ventilation rate desired for cooling $\left(\mathrm{m}^{3} / \mathrm{s}\right)$

$\mathrm{T}_{\text {inside }}$ - temperature inside a building $\left({ }^{\circ} \mathrm{C}\right)$

$\mathrm{T}_{\text {outside }}$ - temperature outside a building $\left({ }^{\circ} \mathrm{C}\right)$

$\mathrm{V}_{\mathrm{Z}}$ - wind speed at height ' $\mathrm{Z}$ ' $(\mathrm{m} / \mathrm{s})$

\section{References}

Awbi, H. (2003). Ventilation of Buildings. 2 ed. Spon Press. London (UK).

CIBSE AM 10 (2005). Applications Manual 10: Natural Ventilation, The Chartered Institution of Building Services Engineers. London (UK).

CIBSE Guide A (2010). Environmental design. The Chartered Institution of Building Services Engineers, London (UK).

CIBSE KS 17 (2011). Knowledge Series 17: Indoor Air Quality \& Ventilation. The Chartered Institution of Building Services Engineers, London (UK).

Climate.OneBuilding.Org. (2014). Repository of free climate data for building performance simulation. New typical year weather data for 62 Indian locations. Available in: http://climate.onebuilding.org/sources/ default.html. [accessed in 20/01/2018].

de Faria, L., Cook, M., Loveday, D., Angelopoulos, C., Manu, S., Shukla, Y. (2018). Sizing natural ventilation systems for cooling: the potential of NV systems to deliver thermal comfort while reducing energy demands of multi-storey residential buildings in India. Proceedings from PLEA2018: Passive and Low Energy Architecture Conference. Hong-Kong (HK), 10-12 December 2018.
Durrani, F., Cook, MJ., McGuirk, JJ. (2015). Evaluation of LES and RANS CFD modelling of multiple steady states in natural ventilation. Building And Environment 92, 167-181.

Heiselberg, P., Sandberg, M. (2006). Evaluation of Discharge Coefficients for Window Openings in Wind driven Natural Ventilation. International Journal of Ventilation 5(1), 43-52.

Ji, Y., Cook, M. (2007). Numerical studies of displacement natural ventilation in multi-storey buildings connected to an atrium. Building Services Engineering Research and Technology 28(3)207-222.

Jiang, Y., Chen, Q. (2003). Buoyancy-driven single-sided natural ventilation in buildings with large openings. International Journal of Heat and Mass Transfer 46 (6), 973-988.

Jiang, Y., Alexander, D., Jenkins, H., Arthur, R., Chen, Q. (2003). Natural ventilation in buildings: measurement in a wind tunnel and numerical simulations with largeeddy simulation. Journal of Wind Engineering Industrial Aerodynamics 91 (3), 331-353.

Jones, B. M., Cook, M. J., Fitzgerald, S. D., Iddon, C. R. (2016). A review of ventilation opening area terminology. Energy and Buildings 118, 249-258.

Lo, L., Banks, D., Novoselac, A. (2012). Combined wind tunnel and CFD analysis for indoor airflow prediction of wind-driven cross ventilation. Building and Environment 60, 12-23.

Manu, S., Shukla, Y., Rawal, R., Thomas, L. E., \& de Dear, R. (2016). Field studies of thermal comfort across multiple climate zones for the subcontinent: India Model for Adaptive Comfort (IMAC). Building and Environment 98, 55-70.

OECD/IEA (2018). The Future of Cooling. Opportunities for energy-efficient air conditioning. International Energy Agency-IEA. Available at: http://www.iea.org/ publications/freepublication/The_Future_of_Cooling. pdf [accessed in 22 May 2018].

Rajan, R. \& Shukla, Y. (2014). Residential Buildings in India: Energy Use Projections and Savings Potentials. Global Buildings Performance Network GBPN, CEPT University. Ahmedabad (India).

Versteeg, H., Malalasekera, W. (2007). An introduction to computational fluid dynamics - the finite volume method. $2^{\text {nd }}$ ed. Harlow. Pearson. London (UK).

Yalkot, V. Orzag, S., Thangham, S., Gatski, T., Speziale, C. (1992). Development of turbulence models for shear flows by a double expansion technique. Phys Fluids A. 4 (7), 1510-20.

Zhai, Z., Zhang, Z., Zhang, W., Chen, Q. (2007). Evaluation of varios turbulence models in predicting airflow and turbulence in enclosed environments by CFD: Part 1 - summary of prevalent turbulence models. HVAC \& R. Res. 13 (6), 853-870. 